\title{
ENSINO DE ZOOLOGIA NAS AULAS DE CIÊNCIAS A PARTIR DA APRENDIZAGEM SIGNIFICATIVA CRÍTICA
}

\section{TEACHING ZOOLOGY AT SCIENCE CLASSES REFERENCE FRAME OF THE CRITICAL MEANINGFUL LEARNING}

\author{
Mariane Soares da Silva ${ }^{1}$, Samuel Costa ${ }^{2}$ \\ ${ }^{1}$ Secretaria Estadual de Educação de Santa Catarina/Professora de Física, \\ mariane.ss1995@aluno.ifsc.edu.br \\ ${ }^{2}$ Intituro Federal de Santa Catarina (IFSC), campus Araranguá/Curso de Licenciatura em Física, \\ samuel.costa@ifsc.edu.br
}

\begin{abstract}
RESUMO
Zoologia é uma temática muito importante no ensino de Ciências, que muitas vezes se apoia em memorização. O desenvolvimento de estratégias diferenciadas em relação ao ensino zoologia, visando o processo de ensino-aprendizagem sobre este tema, foi contemplado sob a luz dos referenciais da Teoria da Aprendizagem Significativa Crítica. Portanto, o objetivo deste trabalho é apresentar uma proposta de atividade didática diferenciada aplicada ao ensino crítico de zoologia durante as aulas de Ciências. A investigação foi realizada em uma escola pública localizada no município de Araranguá/SC, envolvendo 23 alunos, integrantes de uma turma regular de $7^{\circ}$ ano do ensino fundamental. Os dados foram coletados ao longo de todo o processo, com a utilização dos seguintes métodos: i) observação participante, ii) coleta do material produzido pelos alunos; iii) aplicação de questionário. Esta é uma estratégia de ensino que favorece um estreitamento entre a realidade dos alunos e os conceitos científicos, oportuniza a discussão e a formulação de hipóteses, justifica os fenômenos estudados, além de mostrar o papel do professor como orientador.
\end{abstract}

Palavras-chave: Ensino Fundamental. Ensino de zoologia. Estratégias de ensino. Teoria da Aprendizagem Significativa Crítica.

\begin{abstract}
Zoology is a very important field in science education and it is remarkably based on memorization. The development of different strategies in relation to teaching zoology, aimed to teaching-learning process on this topic was considered in this study. These strategies were devised based on the reference frame of the Critical Theory of Meaningful Learning. Therefore, the objective of this paper is to present a proposal for different teaching activity about Critical zoology supported at science classes. The lessonswere conducted in a public school located in the Municipality of Araranguá/SC, involving 23 students, permanent members in the 7 th year of elementary school. The data was collected throughout the process, with the utilization of the following methods: i) participant observation; ii) gathering of material produced by the students; iii) application of survey. This is a teaching strategy favoring a narrowing between the reality of students and scientific concepts, make the discussion and formulation of hypotheses, justify the phenomena studied, and show the role of the teacher as leader.
\end{abstract}

Keywords: Elementary School. Teaching zoology. Teaching strategies. Critical Theory of Meaningful Learning.

\section{INTRODUÇÃO}


O ensino de Ciências da Natureza contribui para a compreensão de fenômenos que acontecem no cotidiano do indivíduo, permitindo o entendimento do mundo em que vive, a partir da leitura dos problemas sociais (DELIZOICOV; ANGOTTI; PERNAMBUCO, 2009), éticos e ambientais. Por isto, nas últimas décadas, vem assumindo papel importante junto à sociedade, tornando-se importante contribuinte para a formação cidadã.

No Ensino Fundamental, os Parâmetros Curriculares Nacionais (PCNs) preconizam que o ensino de Ciências da Natureza tem o objetivo de permitir que o aluno adquira ciência dos conhecimentos científicos e tecnológicos para que, a partir disso, compreenda o mundo de forma que se torne um cidadão capaz de agir crítica e reflexivamente (BRASIL, 1998). Com isso, o indivíduo pode se perceber enquanto um integrante da sociedade capaz de atuar como agente transformador.

Como forma de atingir os objetivos do ensino de Ciências da Natureza os PCNs dividem os conteúdos da unidade curricular de Ciências nos eixos temáticos "Vida e Ambiente", "Ser Humano e Saúde", "Tecnologia e Sociedade" e "Terra e Universo". Tomando como ponto de partida esses eixos, há a possibilidade de se abordar conteúdos que permitam a aquisição de conhecimentos nas áreas de Astronomia, Geologia, Biologia, Física e Química, possibilitando a integração entre aspectos do ambiente, da sociedade, da ciência e da tecnologia, em busca da cidadania.

Para citar um exemplo, o eixo temático "Vida e ambiente" aborda conteúdos ligados à diversidade da vida nos diferentes ambientes terrestres, relacionando os seres vivos e os fatores abióticos, assim como o ser humano com o meio ambiente (BRASIL, 1998), sendo abordados no terceiro ciclo do ensino fundamental, mais especificamente no $7^{\circ}$ ano. Conforme o referido documento, este eixo busca "[...] proporcionar ao estudante a ampliação de conhecimentos sobre os ambientes e seus problemas, sobre os seres vivos, entre eles os seres humanos, e as condições para a vida" (BRASIL, 1998, p. $67)$.

No tema Vida e Ambiente há referência à parte de zoologia recomendado para ser abordado no $7^{\circ}$ ano do Ensino Fundamental. Cabe ressaltar que a zoologia é o ramo da Biologia que estuda os animais nos mais variados aspectos, como os ecológicos, fisiológicos, morfológicos e taxonômicos, ou seja, oportuniza levar aos alunos os conhecimentos científicos que envolvem a vida desses seres vivos.

Justamente por ser um dos temas que precisam ser trabalhados na escola, alguns autores têm realizado estudos buscando evidenciar metodologias e reforçar a 
importância do ensino de zoologia na Educação Básica (e.g. SANTOS; GUIMARÃES, 2010; OLIVEIRA et al., 2011; CARVALHO; BRAGA, 2013; SANTOS; TERÁN, 2013a; 2013b; ROCHA; MAESTRELLI, 2014). O aumento deste tipo de estudo pode ser justificado pelo fato de o ensino dos animais nas escolas propiciarem maior atenção para a conservação e a preservação da biodiversidade, neste caso, a animal. A partir do entendimento de aspectos ecológicos desses seres vivos, por exemplo, há a possibilidade de contribuir de diversas formas para manter e/ou melhorar o ambiente (SANTOS; TERÁN, 2013a).

Apesar de sua importância demonstrada em estudos como os citados, o ensino de zoologia é muito questionado pelo modo que é desenvolvido em sala de aula atualmente. Isso porque, geralmente, a zoologia é abordada nas escolas tendo como fonte de consulta primordial o livro didático (SANTOS; TERÁN, 2013a; 2013b; ROCHA; MAESTRELLI, 2014), resultando na utilização de pouca diversidade de recursos didáticos. Além disso, contribuem para tal situação, a falta de recursos de mídias e multimídia em algumas escolas e de laboratórios apropriados e bem equipados (SANTOS. TERÁN, 2013a). Como consequência, as aulas acabam tendo como base principal a exposição oral, sendo quase ausente, além do uso dos laboratórios, a utilização de espaços não formais como meio de ensino.

Dentre os fatores que também contribuem para a condição atual do ensino de zoologia estão a carência na formação inicial docente que, geralmente, é desconecta da realidade de ensino, a ausência de formação continuada (SANTOS, TERÁN, 2013a), a primazia por nomenclaturas e termos técnicos inerentes à referida área do conhecimento e a valorização de aspectos fisiológicos e anatômicos dos animais (CARVALHO; BRAGA, 2013; ROCHA; MAESTRELLI, 2014) em detrimento aos evolutivos e ecológicos.

Por tudo isso, a situação atual do ensino de zoologia tem resultado, em grande parte, em abordagens meramente memorísticas e descontextualizadas do cotidiano discente, causando a falta de interesse por temas potencialmente atrativos. Algo que pode dificultar a formação de discentes reflexivos, críticos e capazes de exercerem a cidadania. Para Rocha e Maestrelli (2014), por exemplo, o enfoque de zoologia sob a perspectiva autoritária, dogmática, mecânica e acrítica em relação a Ciência e a realidade não subsidia a formação de um sujeito crítico e autônomo.

É possível cogitar que a formação de alunos críticos acerca de temas de zoologia deve iniciar pela superação do modelo clássico de ensino de Ciências da Natureza, o 
qual está baseado na narrativa em que cabe ao professor transmitir e ao aluno receber o conhecimento de forma acrítica e centrar o ensino no aluno, como recomenda Moreira (2011b).

O ensino centrado no aluno preconiza que ele deve assumir a postura ativa no processo de ensino e aprendizado a partir de estratégias didáticas que permitam as discussões, a negociação de significados, a valorização do diálogo e a utilização de atividades colaborativas que conduzam a receber e a realizar críticas. Nesse sentido, Moreira (2011b) argumenta que o docente não deve ser um mero transmissor de conteúdo, mas sim estimular o aluno a construir o próprio conhecimento.

Como meio de centrar o ensino no aluno Moreira (2010; 2011b) recomenda alguns princípios, como: considerar os conhecimentos prévios; abandonar o modelo de aula narrativa (professor transmissor); estimular os alunos a perguntarem; utilizar materiais educativos e estratégias diversificadas; mostrar que o significado parte das ideologias de cada pessoa; utilizar o erro como fator de aprendizagem e não de punição; deixar claro a incerteza do conhecimento humano e; propiciar que os alunos abandonem obstáculos epistemológicos existentes.

Mas como propiciar um ensino de zoologia de maneira que possibilite a formação de alunos críticos a partir da realidade escolar na qual docentes e discentes estão inseridos atualmente? Para descobrir possíveis respostas para tal questão esta investigação objetivou planejar, implementar e avaliar uma sequência didática para o ensino crítico de zoologia a partir da Aprendizagem Significativa Crítica. Para tanto, assumiu-se como ponto de partida as recomendações de Moreira (2010; 2011b).

\section{CAMINHOS PERCORRIDOS}

Para que o objetivo da pesquisa fosse alcançado, assumiu-me o procedimento técnico de pesquisa-ação por propor a resolução na prática de problemas relacionados ao ensino a partir de uma perspectiva crítico-reflexiva-emancipatória (AZEVEDO; ABID, 2013). Desse modo, esta investigação apresentou natureza qualitativa, na qual houve o aprofundamento de uma situação objetivando a compreensão e a explicação das informações (FLICK, 2009).

Cumpre ressaltar que a referida pesquisa foi realizada na cidade de Araranguá (SC), em uma escola da Rede Estadual de Ensino, em uma turma do $7^{\circ}$ ano do Ensino Fundamental, composta por 23 alunos com faixa etária entre 10 e 12 nos. As atividades 
foram realizadas no âmbito do Estágio de Regência em Ciências do curdo de Licenciatura em Ciências da Natureza de uma instituição pública do sul de Santa Catarina.

Os temas delimitados para a abordagem a partir de um ensino de zoologia crítica foram "Introdução aos vertebrados" e "Classe dos peixes". Após, foram observadas quatro aulas na classe escolhida para identificar características do grupo (relação entre alunos, assiduidade, empenho nas atividades e na execução das tarefas, entre outros) que subsidiassem a realização de um planejamento adequado ao seu perfil.

Em seguida, foi planejada uma sequência didática de 12 horas-aula, que foi implementada no primeiro semestre de 2016, distribuída em quatro momentos (Tab. 1).

Tabela 1 - Síntese da sequência didática utilizada para o ensino de zoologia crítico no Ensino

Fundamental.

\begin{tabular}{|c|c|}
\hline \multicolumn{2}{|c|}{ Introdução ao grupo dos vertebrados e Classe dos peixes } \\
\hline Momentos & Atividades \\
\hline \multirow{4}{*}{$\begin{array}{l}\text { Momento } 1 \\
\text { (3 aulas) }\end{array}$} & Levantamento de conhecimentos prévios - questionário sobre os vertebrados \\
\hline & Aula expositivo-dialogada - slide "O que esses animais têm em comum?" \\
\hline & Organizador prévio - história "Ana, a boneca de pano" \\
\hline & Atividade colaborativa - montagem do esqueleto de papel \\
\hline \multirow[t]{3}{*}{$\begin{array}{l}\text { Momento } 2 \\
\text { ( } 2 \text { aulas) }\end{array}$} & $\begin{array}{l}\text { Atividade colaborativa - Atividade prática: distinguir os animais vertebrados dos } \\
\text { invertebrados. }\end{array}$ \\
\hline & $\begin{array}{l}\text { Atividade colaborativa - Atividade prática: separar os animais em classes a partir } \\
\text { das características }\end{array}$ \\
\hline & Diferenciação progressiva e reconciliação integradora - jogo dos vertebrados \\
\hline \multirow{6}{*}{$\begin{array}{l}\text { Momento } 3 \\
\text { (4 aulas) }\end{array}$} & Organizador prévio - apresentação das piranhas taxidermizadas \\
\hline & Aula expositiva-dialogada - slides "Classe dos peixes" \\
\hline & $\begin{array}{l}\text { Diferenciação progressiva e reconciliação integradora - Aula prática: Do que um } \\
\text { peixe é formado? }\end{array}$ \\
\hline & $\begin{array}{l}\text { Reconciliação integradora e avaliação formativa - devolução dos roteiros da aula } \\
\text { prática e discussão das respostas }\end{array}$ \\
\hline & $\begin{array}{l}\text { Diferenciação progressiva e reconciliação integradora - revisão com lista de } \\
\text { exercícios e correção }\end{array}$ \\
\hline & $\begin{array}{l}\text { Diferenciação progressiva e reconciliação integradora - leitura "Por que alguns } \\
\text { peixes vivem apenas em água doce e outros na água salgada?" }\end{array}$ \\
\hline \multirow{3}{*}{$\begin{array}{l}\text { Momento } 4 \\
\text { (3 aulas) }\end{array}$} & Avaliação somativa - trabalho individual e com consulta \\
\hline & $\begin{array}{l}\text { Diferenciação progressiva e reconciliação integradora - leitura "Você sabia que as } \\
\text { piranhas comem vegetais?" }\end{array}$ \\
\hline & Reconciliação integradora - jogo da memória dos peixes \\
\hline
\end{tabular}
Fonte: Autores.

Seguindo as recomendações de Zabala (1998) a sequência didática foi proposta de forma a alcançar os objetivos educacionais com a utilização de atividades ordenadas, estruturadas e articuladas entre si. Para tanto, foram elaborados planos de aulas nos quais as atividades propostas propiciassem a Aprendizagem Significativa Crítica, 
primando pela pluralidade metodológica e pela autonomia discente, cabendo ao docente o papel de mediador do processo.

Cabe ressaltar que o planejamento, a implementação e a avaliação da sequência didática foram realizados sob a luz da Teoria da Aprendizagem Significativa (TAS) de David Ausubel (AUSUBEL, 2003 apud MOREIRA, 2012), acrescidas dos elementos da Aprendizagem Significativa Crítica (MOREIRA, 2010) e da recomendação dos princípios para uma aprendizagem crítica (MOREIRA, 2011b).

A TAS considera que a aprendizagem deve ocorrer na relação não-literal e nãoarbitrária do conhecimento prévio com o conhecimento a se aprender. Em função disso, na elaboração da sequência didática supracitada, foram respeitadas as duas premissas preconizadas pela teoria em questão, ou seja, a pré-disposição do aluno em aprender e a potencialidade significativa do material a ser aprendido (MOREIRA, 2012). Assim, os materiais utilizados no decorrer da sequência (slides, textos, artigos de divulgação científica e atividades em ambientes não formais) foram escolhidos e utilizados de forma a despertar a pré-disposição do aluno em aprender.

Em busca da aprendizagem significativa crítica foram seguidos também os princípios programáticos da diferenciação progressiva e da reconciliação integradora, assim como a utilização de organizadores prévios, conforme orienta Moreira (2012). A diferenciação progressiva aconteceu por meio da organização e apresentação inicial dos conceitos mais gerais e inclusivos, de forma mais ampla inicialmente, sendo progressivamente diferenciados em busca de um grau maior de complexidade.

Concomitantemente, a reconciliação integradora ocorreu nos momentos em que novas informações foram apresentadas em um grau maior de especificidade, permitindo a reorganização de elementos existentes na estrutura cognitiva e a aquisição de novos significados. Já os organizadores prévios funcionaram como materiais introdutórios apresentados antes do material propriamente dito a ser aprendido (MOREIRA, 2012). Estes foram propostos em um nível mais alto de generalização e abstração, servindo como meio entre o conhecimento prévio do aprendiz e o conhecimento científico que se procurou ensinar significativamente.

As estratégias didáticas utilizadas seguiram as recomendações de Krasilchik (2011) em busca do melhor entendimento e compreensão acerca do tema abordado. Sendo assim, foram constituídas de aulas expositiva-dialogadas, aula prática e simulação. 
Durante a implementação da sequência didática foi utilizado o diário de aula para a anotação dos acontecimentos, do comportamento dos alunos, das dúvidas, das curiosidades, dos questionamentos, entre outros, assim como das impressões dos pesquisadores (ZABALZA, 2004). Tal instrumento buscou não perder nenhuma informação oriunda da observação julgada como pertinente, ou seja, que contribuísse com a posterior descrição e análise dos fatos. Além de coletar dados dessa forma, foram utilizados outros instrumentos de pesquisa, como os questionários de conhecimentos prévios e as atividades realizadas no decorrer da sequência didática.

\section{PROPOSTA DE ENSINO DE ZOOLOGIA CRÍTICO}

A sequência didática iniciou propondo formas diferentes para que os alunos expusessem seus conhecimentos prévios sobre os vertebrados a fim de verificar se eles eram aceitos ou não no âmbito da disciplina de Ciências. Para tanto, foi utilizado um questionário de conhecimentos prévios respondidos pelos discentes presentes com os seguintes questionamentos: O que diferencia um animal vertebrado de invertebrado?; Quando um animal é considerado vertebrado?; Onde podem ser encontrados os animais vertebrados? e; Cite alguns vertebrados que você conhece do dia a dia.

Os conhecimentos prévios contribuíram para o (re)planejamento da sequência didática, assim como em seu processo de implementação. Isso porque, a partir deles, foi possível adequar as situações de aprendizagem ao cotidiano. O conhecimento prévio permitiu também que os novos conhecimentos apresentados aos alunos fossem significados a partir da ancoragem dos últimos nos primeiros (MOREIRA, 2011a; 2011b; 2012), de forma que não fosse imposto, ou seja, arbitrário. Para além do exposto, Pelizzari et al. (2002) afirmam que o estabelecimento de conexões entre os conhecimentos prévios e os científicos permite a apreensão de novos conceitos, a partir dos quais a consolidação do que foi aprendido ocorrerá com a introdução de novos elementos.

Ao término do preenchimento do questionário, foi dado início à aula expositivadialogada sobre vertebrados. Assim, inicialmente foi exposto um slide com figuras de diversos animais vertebrados e questionado: "O que estes animais têm em comum?”. A partir deste questionamento, que serviu para a reflexão discente, foram realizadas as atividades em nível introdutório, considerando os conhecimentos prévios levantados no processo anterior. 
A pergunta serviu para que os alunos analisassem as características específicas de cada grupo dos vertebrados. Quando questionados, eles responderam que os animais que estavam presentes no slide tinham em comum o fato de terem ossos. Cabe ressaltar que a veracidade das respostas dadas por eles não foi questionada naquele momento, pois a pergunta deveria ser respondida a partir de suas próprias conclusões.

O questionamento inicial serviu para suscitar o diálogo e a discussão, aproximando alunos e alunos, alunos e professor, e alunos e o tema. Para Moreira (2010; 2011b), o ensino centrado no aluno está condicionado a situações e circunstâncias que possibilitem a participação ativa e o posicionamento a partir de estratégias que conduzam às discussões, sob a mediação docente.

Com o intuito de subsidiar a resposta para o questionamento inicial foi disponibilizada e discutida a adaptação do texto "Ana, a boneca de pano", que conta a história de uma boneca de pano que não apresentava sustentação que a permitisse ficar em pé. Então, foi perguntado aos alunos por que isso acontecia, sendo que a primeira resposta foi a de que ela não era um ser vivo. Em seguida, após reflexões e discussões em grupo, os discentes afirmaram que mesmo que fosse um ser vivo não poderia ficar de pé porque não tinha ossos que a sustentasse, pois era apenas de pano.

Esse ponto abriu discussão para outros tópicos da aula, como a estrutura do corpo formada pelo esqueleto, a diferença entre endoesqueleto e exoesqueleto e a coluna vertebral. Em meio às explicações sobre esses pontos, os alunos questionaram o número de ossos que o ser humano possui. Nesse momento, notou-se que estavam relacionando o cotidiano a partir de reflexões próprias por meio das colocações realizadas por eles.

Cumpre destacar que a história descrita acima serviu como organizador prévio, pois foi utilizada como material instrucional introdutório de forma generalista. Assim, essa etapa exerceu a função de servir como ponte entre o que o aluno já sabia e o novo conhecimento, objetivando que ele estabelecesse relações no intuito de aprender significativamente (MOREIRA, 2011a; 2012).

Os organizadores prévios podem ser materiais que não são familiares aos discentes, atuando como expositores do novo conceito a ser aprendido, ou podem ser familiares, sendo que nesse último caso integrará as novas ideias e os conhecimentos presentes na estrutura cognitiva discente (MOREIRA, 2012). Neste caso, o texto cumpriu o papel de expor um novo conhecimento. Para isto, conforme recomendações de Ausubel (2003 apud MOREIRA, 2012), o texto foi escolhido considerando a 
realidade da turma, ou seja, a idade do público e o grau de familiaridade com o conceito a ser aprendido.

Dando prosseguimento, foi apresentado o restante dos slides aos alunos, a partir dos quais foram discutidos diversos temas suscitados durante as atividades anteriores, além de novos conceitos. Foram abordados tópicos, como a diferença de endoesqueleto e exoesqueleto, a coluna vertebral e a importância dela e o crânio, por meio de exemplos. Naquele momento, os alunos foram questionados se todos os animais que possuem esqueleto eram considerados vertebrados. Inicialmente, eles ficaram um pouco confusos em relação à questão, por isso, a fim de elucidar tal fato, foi explicado que os animais que possuem exoesqueleto não são considerados vertebrados e parte do grupo dos invertebrados.

No final da aula expositiva-dialogada foi retomada a questão inicial sobre as principais características comuns a todos os vertebrados. A partir dos conhecimentos discutidos e apresentados, os discentes conseguiram responder corretamente à questão, salientando as semelhanças. Além disso, durante toda esta aula as perguntas utilizadas no questionário de conhecimentos prévios foram retomadas.

Finalmente, a última parte do primeiro momento da sequência didática foi destinada a atividade de montagem modelos didáticos de esqueletos humanos para que os discentes observassem a forma como essa estrutura se constitui.

Para a realização de tal atividade, os alunos foram divididos em grupos, recebendo cada um uma cartolina e um modelo didático de esqueleto humano para recortar, colar e montar o esqueleto unindo as partes com barbantes. Após o término da atividade, os esqueletos foram pendurados na parede e alguns aspectos biológicos sobre eles foram discutidas, como a função nos vertebrados, ligando com a história da boneca de pano.

Cabe ressaltar que a utilização de um modelo didático foi proposta, pois no ensino de Ciências eles facilitam a compreensão do conteúdo em questão, desde que sejam dimensionados e abordados significativamente. Como benefícios desse recurso didático nas aulas de Ciências Justina e Ferla (2006) e Cavalcante e Silva (2008) salientam que, além de permitir a experimentação, eles desenvolvem habilidades e competências que contribuem com a alfabetização científica, algo que possibilita a formação de indivíduos com relação reflexiva com o mundo que os cerca.

Entretanto, Krasilchick (2011) chama a atenção para a utilização correta desse recurso didático, pois, caso ocorra incorretamente, pode levar ao entendimento errôneo 
do conteúdo enfocado. Por isso, para evitar o entendimento de que os modelos didáticos são simples representações do real é importante que os alunos construam o próprio modelo sob a orientação e mediação docente. A partir disso, a atividade da montagem dos esqueletos foi planejada para que os próprios alunos a realizassem, verificando os ossos e a importância deles para a sustentação do corpo dos vertebrados.

Durante a realização da atividade, os alunos mostraram empenho e interesse, características importantes para a Teoria da Aprendizagem Significativa Crítica, na medida em que uma de suas premissas básicas é a predisposição para aprender (MOREIRA, 2012). Afinal, quando o indivíduo demonstra interesse junto ao assunto que é exposto, tende a manifestar dedicação às atividades relacionadas ao tema e a identificação com ele.

É importante salientar também que a atividade de montagem do esqueleto serviu como reconciliação integradora. Assim, oportunizou a organização do conhecimento de forma hierárquica na estrutura cognitiva (MOREIRA, 2012), permitindo a relação entre os conceitos de forma que sejam percebidas as similaridades e as diferenças entre eles, ocasionando a reconciliação de possíveis discrepâncias e a aquisição de significados novos (MOREIRA, 2011a).

O segundo momento da sequência didática iniciou com a colocação no fundo da sala de um painel de papel pardo dividido em duas colunas denominadas vertebrados e invertebrados. Por sua vez, a coluna dos vertebrados foi subdividida nas cinco classes existentes de vertebrados: peixes, anfíbios, répteis, aves e mamíferos.

O referido painel foi utilizado para a execução da atividade colaborativa intitulada “Invertebrados ou vertebrados? Por quê?". Para a realização desta atividade, os alunos ficaram sentados na frente do painel, sendo que cada um recebeu duas figuras aleatórias de vertebrados e/ou invertebrados. Em seguida, no momento adequado, cada um colou no painel a imagem na coluna que acreditou estar correto, sendo posteriormente justificada a escolha e discutida junto aos demais colegas.

Vale evidenciar que as atividades que requerem a colaboração entre os alunos permitem que eles expressem por meio da linguagem as relações que estabelecem em sua estrutura cognitiva. Com o compartilhamento de conhecimentos há a possibilidade de haver um espaço de negociação de significados, além de permitir a realização e a recepção de críticas de e a outros colegas. Essa postura ativa facilita o emponderamento do conhecimento. 
Com os conhecimentos compartilhados nas aulas anteriores, os alunos distinguiram os grupos aos quais pertenciam os animais recebidos, ou seja, disseram se eram invertebrados ou vertebrados, além de identificarem a classe a qual o vertebrado pertencia, justificando tal fato. Essa atividade aguçou a curiosidade dos alunos sobre os animais das imagens utilizadas, como por exemplo, a velocidade que o beija-flor bate as asas, as características dos mamíferos marsupiais, a classe a qual pertence o ornitorrinco, usando como exemplo um desenho animado, e o fato de a baleia ser uma mamífero que aquático e não um peixe.

A seguir foi realizado o "Jogo dos vertebrados" que consistiu em perguntas e respostas sobre o grupo dos vertebrados (Quadro 1).

Quadro 1 - Questões utilizadas na atividade colaborativa "Jogo dos vertebrados".

1. Qual é a principal diferença entre o esqueleto de um gato e de um caranguejo?

2. Qual é a principal característica que faz tanto o gato quanto o peixe serem considerados vertebrados, assim como o caranguejo e a barata, invertebrados, apesar de todos eles terem algum tipo de esqueleto?

3. Qual a classe de vertebrados apresenta maior número de espécies registradas?

4. Qual a classe de vertebrados apresenta menor número de espécies registradas?

5. A qual classe dos vertebrados o ser humano pertence?

6. Quais são as três estruturas apresentadas pelas aves, anfíbios, mamíferos, peixes e répteis que os fazem ser vertebrados?

7. Dê exemplo de cinco animais que possuem endoesqueleto?

8. Dê exemplo de cinco animais que possuem exoesqueleto?

9. Todo animal que possui esqueleto é considerado vertebrado? Por quê?

10. Como é chamada a fileira de ossos existente no interior do corpo dos vertebrados?

Para a realização do jogo, a turma foi dividida em dois grupos (A e B), cada pergunta foi respondida inicialmente com base nos conhecimentos compartilhados até aquele momento da sequência didática. Quando isto não foi possível, foi dada a possibilidade de pesquisar no livro didático e no caderno. Como regra, a resposta incorreta de um grupo daria a possibilidade do outro responder, sem que o primeiro perdesse ponto. Dentre as perguntas realizadas, apenas a questão três, sobre a classe de vertebrados com maior diversidade de espécies, foi respondida de forma incorreta.

No decorrer da realização do jogo didático, a turma se mostrou muito participativa, atenciosa e colaborativa. Assim, tal atividade foi bem produtiva e bastante importante para se atingir a reconciliação integradora, além de proporcionar a realização de uma avaliação formativa. Isso porque, em cada erro ou imprecisão na resposta, foram pontuados aspectos que contribuíram para a elucidação da dúvida e correção dos conceitos.

O terceiro momento foi iniciado com a retomada dos conceitos trabalhados anteriormente, como o grupo dos vertebrados, as classes que o compõe e as 
características desses animais, contribuindo com a reconciliação integradora. A partir disso, foram sendo inseridos novos conceitos, de forma que o aluno adquirisse novos conhecimentos na medida em que, ao se deparar com algo novo e desconhecido, buscasse compreendê-lo a partir das ideias mais amplas se direcionando as mais específicas, permitindo o alcance da diferenciação progressiva.

A retomada dos conceitos objetivou também a consolidação que se constitui como um dos princípios que propiciam a Aprendizagem Significativa Crítica. Segundo Moreira (2011a; 2012), este princípio consiste na necessidade de insistir no que está sendo estudado, antes da apresentação de novos conceitos, contribuindo para o êxito da aprendizagem. Na ocasião, foram percebidos indícios desse princípio, pois os alunos respondiam de forma correta aos questionamentos realizados.

Por conseguinte, foi iniciado o tema "Classe dos peixes" com a observação de duas piranhas taxidermizadas, utilizadas como materiais potencialmente significativos que serviram como organizadores prévios. Para que o material se tornasse potencialmente significativo durante a atividade foi solicitado que os alunos observassem e anotassem características inerentes aos peixes, como a presença de escamas, a posição de olhos, das narinas e da boca, a existência e quantidade de nadadeiras, a presença da linha lateral, para posteriores discussões.

A apresentação de novos significados aos alunos a partir de um material de ensino potencialmente significativo permitiu a percepção da relevância do tema. A partir disso, foi percebido que houve a intencionalidade ou pré-disposição em aprender, possibilitando um movimento em direção ao ensino de zoologia crítico. Para Moreira (2011b), a Aprendizagem Significativa Crítica ocorre somente a partir do momento em que o aluno não aceitar de forma passiva os novos conhecimentos apresentados, refletindo sobre o que está sendo abordado.

Ao término da observação dos exemplares de piranhas, por meio de uma aula expositiva-dialogada com o auxílio de slides, foram apresentadas as principais características dos peixes, os tipos de habitats, a forma de locomoção e a estrutura óssea. Em seguida, foram explanados aspectos anatomo-fisiológicos com o cuidado para que não fosse valorizada a difusão de nomes difíceis e a memorização.

A realização dessa aula inicial sobre peixes buscou abandonar o que Rocha e Maestrelli (2014) denominam de ensino bancário da vida animal. Dessa forma, procurou-se deixar a neutralidade, a inércia e a atemporalidade do conhecimento científico e problematizá-lo com “[...] as intencionalidades, ideologias e seus efeitos 
concretos na vida cotidiana [...]" (p.585). Com isso, objetivou-se não primar e não valorar as nomenclaturas e os termos técnicos que, muitas vezes, contribuem para o ensino de zoologia autoritário, dogmático e mecânico, conforme ressaltam Carvalho e Braga (2013) e Rocha e Maestrelli (2014).

$\mathrm{Na}$ sequência, foi entregue um material de apoio aos alunos sobre a Classe dos peixes, que consistia em um resumo, no qual foram registrados os conceitos abordados na aula anterior. Tal material serviu para consulta durante a realização da aula seguinte e para contribuir com a reconciliação integradora.

No início da aula seguinte, os alunos foram divididos em quatro grupos. Então, um representante de cada grupo foi ao quadro e registou o nome de cada um dos membros como forma de organização da atividade que aconteceria posteriormente. Em seguida, foi entregue a cada grupo o roteiro de uma aula prática sobre os peixes. $\mathrm{O}$ roteiro orientava a análise externa e interna de um peixe que faz parte do cotidiano dos alunos e é muito utilizado como fonte econômica e alimentícia, no caso a tainha (Mugil sp.).

O roteiro foi composto por questões (Explique em poucas palavras como é a respiração dos peixes, destacando o órgão observado que é responsável por essa função; Para que servem as narinas observadas no peixe?; Após a observação do exemplar, você verificou que o peixe tem endo ou exoesqueleto? Justifique.; Qual a função da bexiga natatória observada no peixe?; Para que serve a linha lateral dos peixes?; O que recobre o corpo dos peixes e para que servem as nadadeiras? e; Faça um pequeno texto descrevendo a aula prática de hoje, destacando o que foi observado) e esquemas simplificados de um peixe para que completassem com as principais estruturas interna e externa do animal observado. Esses questionamentos buscaram relacionar a aula prática com os conteúdos anteriormente abordados, de forma que tal estratégia didática não ficasse desconectada do todo e que fosse possibilitada a realização tanto da reconciliação integradora quanto da diferenciação progressiva.

Devido à inexistência de laboratório de ciências na escola, os grupos foram alocados no refeitório para a realização da aula prática supracitada. Lá, cada um recebeu um exemplar do peixe, luvas de procedimento e uma bandeja branca. Primeiramente, os alunos analisaram externamente a estrutura do animal, preenchendo e completando um desenho esquema de um peixe com as principais características observadas. Após, o peixe foi aberto com o auxílio da docente estagiária, para que fosse possível evidenciar 
os principais órgãos e estruturas internas típica dos peixes, como a bexiga natatória, as brânquias, entre outras.

Optou-se pela realização dessa atividade, visto que, no ensino de Ciências, as aulas práticas se constituem como estratégias didáticas que objetivam a compreensão dos conceitos de forma que o aluno seja ativo nesse processo, a partir da manipulação de materiais e equipamentos e pela observação de organismos (KRASILCHIK, 2011). Dentre os papéis desempenhados por tal estratégia didática, a autora citada elenca o de despertar e manter o interesse discente, o de compreender os conceitos básicos a partir de observações e o de desenvolver habilidades que compõem conteúdos atitudinais e procedimentais. Além disso, Andrade e Massabni (2011) argumentam que esta atividade oportuniza a reestruturação dos conhecimentos prévios a partir da busca, da reformulação e da reflexão, desde que seja realizada de forma crítica.

A aula prática sobre peixes realizada junto aos alunos possibilitou observar diversos dos papéis elencados. Por exemplo, os alunos mantiveram o visível interesse durante todo o tempo e realizaram perguntas oriundas de sua curiosidade. Além disso, os discentes demonstraram compreensão do assunto e relacionaram os conhecimentos construídos nessa atividade com os conceitos abordados nas aulas expositivadialogadas.

Apesar da inegável importância das aulas práticas ou experimentais é muito comum constatar a pouca usabilidade dela no âmbito do ensino de Ciências (e.g ANDRADE; MASSABNI, 2011; LIMA; SIQUEIRA; COSTA, 2013), assim como especificamente no ensino de zoologia (SANTOS; TERÁN, 2013a). Nesse sentido, a carência de aulas práticas sobre os temas da zoologia se constituem como uma das dificuldades no processo ensino-aprendizagem, contribuindo para a problemática instaurada no ensino dessa subárea das Ciências da Natureza (SANTOS; TÉRAN, 2013a).

A aula posterior se caracterizou como "Revisão". Nela, foram retomados os aspectos mais gerais e que foram estruturantes nas abordagens anteriores a partir de uma lista de questões relacionadas ao grupo dos vertebrados e a classe dos peixes, temas explanados até aquele momento. Tal atividade serviu como forma de alcançar a reconciliação integradora, com a utilização de exemplos novos, que diferenciaram das situações apresentadas anteriormente, em busca de maior grau de complexidade.

Após a execução da atividade pelos alunos, ela foi corrigida junto ao grande grupo de forma a contribuir com a execução de atividades colaborativas e oportunizar a 
realização e o recebimento de críticas. Além disso, os exercícios proporcionaram aos alunos a possibilidade de tirar dúvidas referentes aos temas abordados durante as aulas anteriores, pois as perguntas presentes na lista de exercícios eram referentes às primeiras aulas ministradas. Este é um ponto muito importante na aprendizagem significativa, isto é, a recursividade que possibilita repetir as tarefas, aproveitando o erro como recurso para a aprendizagem. Nesse caso, os equívocos vistos no roteiro de aula prática e nas aulas de introdução aos vertebrados foram retomados, possibilitando a percepção dos erros pelos alunos.

A última atividade do terceiro momento consistiu na leitura e discussão do texto de divulgação científica (TDC) intitulado "Por que alguns peixes vivem apenas na água doce e outros, na água salgada?" (GASPARINI, 2010). O texto versou sobre as adaptações no organismo dos peixes para viver no ambiente salgado ou doce, assim como sobre o hábitat desses animais.

A partir da leitura do TDC ocorreu uma discussão relativa às principais informações contidas no material, sendo destacados os conceitos considerados chave, assim como sanadas as dúvidas. Nessa atividade, a participação dos alunos foi intensa, resultando em debates reflexivos profícuos. À docente, coube atuar como mediadora conduzindo e estimulando o debate por meio de questionamentos que permitiram aos alunos externalizarem opiniões e participarem de forma ativa.

O TDC foi escolhido por ser um recurso que pode compor facilmente diferentes estratégias didáticas, por ser diferente do texto apresentado pelo livro didático. Além disso, foi utilizado, pois o emprego desse gênero textual nas aulas de Ciências permite o contato com diversos textos e diferentes formas de apresentar o conhecimento científico, possibilitando o acesso a uma gama de informações apresentadas de diferentes maneiras.

Alguns autores (e.g. MARTINS; CASSAB; ROCHA, 2001; MENEGAT; CLEMENT; TERRAZZAN, 2007; FUJII; CORRAZZA， 2011; FERREIRA; QUEIROZ, 2012) destacam ainda que os TDCs podem trazer diversos benefícios importantes para as aulas de Ciências. Dentre os citados por eles, foram percebidos junto aos alunos a possibilidade de contato com conceitos e terminologias científicas, o desenvolvimento da capacidade de argumentação, a transposição do conhecimento para o cotidiano, a mobilização dos conhecimentos para solucionar situações-problemas, o estímulo à criticidade e à fomentação de debates e discussões em sala de aula. 
O texto utilizado permitiu o estabelecimento de inter-relações entre Ciência, Tecnologia, Sociedade e Ambiente (CTSA), a partir da abordagem de diferentes aspectos, de cunho científico, tecnológico, social, econômico, histórico, ético, filosófica e moral. Nesse contexto, Fujii e Corrazza (2011) argumentam que no tocante aos aspectos relacionados à CTSA, o referido gênero textual contribui para abordar quatro diferentes dimensões sob este enfoque.

O quarto e último momento foi constituído de três atividades: avaliação somativa, leitura e discussão de TDC e Jogo da memória.

A avaliação somativa individual foi formada por dez questões que foram respondidas com base em materiais de apoio (livro didático, TDC e texto de revisão). Elas buscaram colocar os alunos em contato com situações diferentes das vistas em aula. A avaliação não serviu apenas para medir o conhecimento, mas também para verificar o empenho dos alunos e averiguar o reflexo do desenvolvimento das aulas e da eficiência das metodologias utilizadas.

O instrumento avaliativo foi concebido considerando a sugestão de Luckesi (2011) que recomenda que a avaliação não pode ser pensada como exame final e classificatório, uma vez que não tem o papel de selecionar, mas de contribuir com o ensino e verificar a aprendizagem. Por isso, a avaliação deve ser concebida como um auxílio para os professores e discentes, afinal, é a partir dela que se avalia não só a aprendizagem discente, mas também a eficácia dos métodos e práticas docentes.

Além da avaliação somativa, ao longo da implementação da sequência didática, foi realizada a avaliação formativa que acompanhou "[...] em que medida está ocorrendo à aprendizagem (significativa, crítica), é processual, contrariamente à somativa que é final. A recursividade permite que o aprendiz refaça as tarefas de aprendizagem, aproveite o erro como fator de aprendizagem" (MOREIRA, 2011b, p. 13). Assim, ao longo do processo, foram registrados acontecimentos que indiciavam a ocorrência de aprendizagem significativa e as dificuldades apresentadas pelos discentes.

A avaliação da aprendizagem significativa deve ser realizada com o objetivo de evidenciar os indícios da aprendizagem significativa (MOREIRA, 2011a; 2011b) e não a existência dela em si. Isso se justifica conforme Lemos e Moreira (2011) pelo caráter progressivo, não-literal e não-arbitrário da aprendizagem significativa que requer tempo para se avaliar o processo de aprendizagem. Assim, para que, após a interação entre o conhecimento prévio e o conhecimento novo, se afirme que houve aprendizado significativo, é preciso que se dê tempo para os conceitos saírem de uma espécie de 
zona difusa e se acomodem na estrutura cognitiva do indivíduo. Nessa etapa, há a existência concomitante de significados contextualmente aceitos e não aceitos. Por isso, no primeiro momento, a avaliação é realizada na busca de indícios desse tipo de aprendizagem e não de certezas.

A segunda atividade do último momento constituiu-se na leitura e discussão do TDC “Você sabia que as piranhas também comem vegetais?” (PORTO, 2007). Este texto serviu para resgatar algumas dúvidas que surgiram durante as observações das piranhas no momento anterior, como por exemplo, se todas as piranhas eram carnívoras.

Por meio das atividades realizadas com a utilização dos TDC foi evidenciado, ao contrário do que se repercute entre muitos docentes de Ciências (observação pessoal dos autores), que os alunos apresentaram interesse significativo pela prática da leitura e discussão. Tal situação pode ter sido facilitada por três fatores: a) linguagem do texto de fácil compreensão; b) a relação do texto com a aula inicial do momento três; e c) a abordagem de um tema levantado pelos próprios alunos no decorrer da sequência didática.

Os PCNs de Ciências (BRASIL, 1998) recomendam a utilização de diferentes fontes de informações, de forma a evitar a utilização excessiva do livro didático. A partir disso, há a possibilidade de o aluno obter informações diferenciadas que o conduza à formação de ideias e atitudes, ao desenvolvimento de opiniões relativas à determinado conhecimento e à formação científica crítica para a convivência social.

Cabe ressaltar também que a escolha para a leitura e a discussão dos dois textos que compõem esta sequência didática considerou as argumentações de Santos e Terán (2013a). Aqueles autores afirmam que "é papel da escola, tentar desfazer a ideia de que o homem é superior aos seres vivos" (p. 6), a partir da valoração da importância ecológica dos animais e importância inerente da espécie. Corroborando, estes autores afirmam ainda que é necessário desprender atenção para aspectos de conservação e de preservação da biodiversidade, possibilitando assim, contribuir com a sustentabilidade ambiental.

Na parte final do último momento, a turma foi dividida em quatro grupos. Cada grupo recebeu um Jogo da memória. O jogo consistia em formar pares nos quais em uma das cartas estava presente uma figura e na outra a descrição das características ou função, por exemplo, em uma carta estava a imagem da bexiga natatória e na outra a descrição da função exercida por ela, buscando a reconciliação integradora. Os alunos com maiores acertos de cada grupo formaram um novo grupo, para a rodada final, que 
foi realizada com toda a turma. Assim, foi conhecido o discente que relacionou mais pares corretamente.

O Jogo da memória, assim como descrito anteriormente, serviu como elemento de motivação e descontração, possibilitando despertar o interesse do público-alvo pelos conteúdos de forma lúdica a partir da mobilização de conhecimentos, além de permitir a interação e a relação social entre os discentes, de forma colaborativa.

No processo de ensino e aprendizagem os jogos, em conjunto com outros recursos didáticos, permitem que os alunos tenham maior interesse pelos conteúdos, facilitando a aprendizagem (CUNHA, 2012). Nesse processo, o docente adéqua o jogo para o fim educativo de forma que cumpra o papel didático, além de mediar a utilização em sala de aula.

Mais especificamente no ensino de Ciências da Natureza, os jogos didáticos têm recebido atenção nos últimos anos, revelando diversos benefícios na ocasião da utilização. Dentre os benefícios evidenciados por Teazani (2006) e Cunha (2012) podem ser citados: estimular o interesse do aluno; auxiliar na construção de conhecimentos; favorecer a interação social dos alunos; despertar o interesse na busca de conhecimentos; estimular a solidariedade, o respeito ao outro e o trabalho em grupo; tornar o aluno indivíduo ativo e autônomo na busca do conhecimento e; favorecer o aprendizado de forma lúdica, interativa e prazerosa. Estes benefícios foram percebidos na execução do jogo didático supracitado, sendo em diferentes intensidades.

A realização de atividades colaborativas, como o jogo didático, por exemplo, fez com que os alunos trabalhassem em conjunto, negociando os objetivos e os resultados da atividade em prol do grupo. Desse modo, houve a possibilidade de fazê-los perceber a importância da ajuda mútua, da responsabilidade compartilhada e da participação nos conhecimentos de forma reflexiva. Essas também foram evidências percebidas por outros autores que utilizaram jogos didáticos para o ensino de zoologia (e.g. SANTOS; GUIMARÃES, 2010; CARVALHO; BRAGA, 2013; BARRETO et al., 2013).

Em relação ainda a esse tipo de atividade, Moreira (2011b) salienta que as etapas de colaboração, discussão e a busca por consensos permite a captação de significados. Durante a discussão dos resultados com o grande grupo, há ainda a submissão à crítica dos outros discentes, oportunizando a argumentação e autocrítica. Finalmente, a utilização de jogos oportuniza a reformulação dos conhecimentos apresentados anteriormente e a percepção de que o ensino e a aprendizagem dos conteúdos dependem da participação ativa do próprio aluno e dos colegas. 


\section{CONSIDERAÇÕES FINAIS}

A busca por um ensino de zoologia crítico passa pela superação da característica meromística e descritiva dele, além de suplantar o comprometimento histórico com a visão autoritária, dogmática, mecânica e hostil da natureza e se tornar uma fonte de análise crítica sobre a Ciência e a realidade (ROCHA; MAESTRELLI, 2014). Para Moreira (2011b) para a superação dos fatos acima o ensino deve ser centrado no aluno valorizando atividades colaborativas e a avaliação formativa de forma propiciar a Aprendizagem Significativa Crítica.

O abandono do ensino centrado no professor, no qual este é um mero transmissor de conhecimento, é um grande desafio, pois isso ainda é bastante comum no ensino de Ciências clássico. Apesar de por vezes o professor adotar estratégias diferenciadas, como slides, por exemplo, ainda acaba adotando o modelo préestabelecido e tendencioso. Com isso, no âmbito escolar o professor por vezes acaba estabelecendo o que o aluno deve memorizar e reproduzir em provas e exames finais de forma acrítica (MOREIRA, 2010; MOREIRA, 2011b).

A partir da implementação da sequência didática descrita na seção anterior é possível apontar que de alguma forma os princípios para uma aprendizagem crítica pelos alunos apontados por Moreira (2011b) a partir de Moreira (2010), foram alcançados.

A consideração dos conhecimentos prévios permitiu que o ensino de zoologia partisse do conhecimento presente na estrutura cognitiva discente, contribuindo com a aprendizagem significativa e, por conseguinte com o aprender criticamente. Várias foram as situação que permitiram a externalização deste conhecimento pelos alunos, como no questionário inicial sobre vertebrados, na utilização do pergunta inicial no momento seguinte "O que estes animais têm em comum?", na atividade de classificação dos animais, por exemplo. Foi evidenciado que nessas e em várias outras situações os

alunos fizeram conexões sobre o que estavam aprendendo e o que já conheciam, permitindo a ancoragem entre os dois conhecimentos.

Os princípios do abando da "narrativa" (professor transmissor) e do estímulo à realização de perguntas foram favorecidos pela criação de situação que privilegiaram o diálogo e a discussão entre os alunos e desses com o docente. A partir disso, os alunos passaram a questionar e a elaborar justificativas e discuti-las junto ao grande grupo. 
Contribuíram para esse fato a realização de diversas atividades colaborativas, como os jogos e a montagem do modelo didático do esqueleto, e os questionamentos realizados no decorrer do processo.

A utilização de materiais e de estratégias didáticas diversificadas estiveram presente no decorrer de toda a implementação da sequência didática. Esses dois princípios propiciaram maneiras diferentes de aprendizado dos conteúdos, de forma que fizessem sentido para os alunos, conduzindo-os assim, para uma aprendizagem significava a partir da pré-disposição em aprender. Para tanto, as estratégias e os materiais potencialmente significativos foram planejados considerando a heterogeneidade e os conhecimentos prévios discentes. Cabe ressaltar que conforme recomenda Moreira (2011b) houve a possibilidade de oferecer explicações sob diferentes perspectivas e autores, além de dificultar a monotonia metodológica que não estimula a criticidade.

O aproveitamento do erro como fator de aprendizagem, a noção de que o conhecimento humano é incerto e a demonstração que o significado está nas pessoas, obtidos a partir das avaliações formativa e somativa permitiram que as relações estabelecidas durante as aulas fossem entendidas como construções próprias que poderiam ser reelaboradas, não se caracterizando como algo linear e pronto em definitivo, favorecendo noção de construção do conhecimento. Com isso, foi oportunizada aos alunos a percepção de que o erro serve como meio de encontrar outra explicação com a modificação ou melhora da anterior e sendo isso obtido a partir da “desaprendizagem". Assim, foi estimulado o abandono de obstáculos epistemológicos que pudessem dificultar a Aprendizagem Significativa Crítica.

Além de contribuir para a superação do papel de transmissor do professor e receptor dos alunos, a utilização dos nove princípios propostos por Moreira (2011b) também se caracterizou como um caminho promissor para a superação das dificuldades encontradas atualmente no ensino de zoologia, dentre as quais Santos e Terán (2013a) destacam: a) uso restringido de como fazer uso da transposição didática de temas de zoologia, b) prática de ensino descontextualizado, c) falta de integração entre os assuntos abordados, d) carência da utilização de aulas práticas sobre os assuntos da zoologia, e) ausência de utilização de materiais didáticos apropriados e f) valorização dos aspectos taxonômicos e nomenclaturais em detrimento aos ecológicos e evolutivos, por exemplo. 
A partir dessa modificação e da utilização dos aspectos anteriormente mencionados foi possível a realização de um ensino de zoologia crítico. Para tanto, para que isso possa ocorrer deve ser adotada uma atitude de ensino centrada no aluno, imbricada da utilização de uma postura docente crítica, reflexiva e problematizadora. E assim poderá ser possível atingir o principal objetivo do ensino de Ciências da Natureza: desenvolver um indivíduo crítico, autônomo, alfabetizado cientificamente e capaz de atuar como agente transformador da realidade na qual está inserido.

\section{REFERÊNCIAS}

ANDRADE, M. L.F.; MASSABNI, V. G. O desenvolvimento de atividades práticas na escola: um desafio para os professores de ciências. Ciência \& Educação, v.17, n. 4, p. 835-854, 2011.

AZEVEDO, M. N.; ABID, M. L. V.S. Pesquisa-ação de a elaboração de saberes docentes em ciências. Investigações em Ensino de Ciências, v. 18, n. 1, p. 55-75, 2013.

BARRETO, L.M.; GAVA, M.; FERRARINI, T.D.; SANTOS, C.M; FERREIRA, C.D.;CARMASSI, A. Jogo didático como auxílio para o ensino de zoologia de invertebrados. In: CONGRESSO INTERNACIONAL DE CIÊNCIAS BIOLÓGICAS, 1., Recife, 2013. Anais... Recife, 2013.

BRASIL. Secretaria de Educação Fundamental.Parâmetros curriculares nacionais: Ciências Naturais. Brasília : MEC/Secretaria de Educação Fundamental, 1998.

CARVALHO, E.F.F.; BRAGA, P.E.T. O jogo de tabuleiro como uma estratégia auxiliadora para o ensino de zoologia, como ênfase para as serpentes. Ensino, Saúde e Ambiente, v.6, n.3, p.202-217, 2013.

CAVALCANTE, D. D.; SILVA, A.F.A. Modelos didáticos e professores: concepções de ensino-aprendizagem e experimentações. In: ENCONTRO NACIONAL E ENSINO DE QUÍMICA, 14., Curitiba, 2008. Anais... Curitiba, 2008.

CUNHA, M. B. Jogos no Ensino de Química: Considerações Teóricas para sua Utilização em Sala de Aula. Química Nova na Escola, v. 34, n. 2, p.92-98, 2012.

DELIZOICOV, D.; ANGOTTI, J. A.; PERNAMBUCO, M. M. Ensino de ciências: fundamentos e métodos. 3 ed. São Paulo: Cortez, 2009.

FERREIRA, L.N.A.; QUEIROZ, S.L. Textos de divulgação científica no ensino de ciências: uma revisão. Alexandria, v. 5, n. 1, p. 3-31, 2012.

FLICK, W. Introdução à pesquisa qualitativa. 3.ed. Artmed: Porto Alegre, 2009.

FUJII, R.A.X.; CORRAZZA, M.J. Célula-Tronco na revista Ciência Hoje: um recurso didático-pedagógico alternativo para o ensino. In: ENCONTRO NACIONAL DE PESQUISA EM EDUCAÇÃO EM CIÊNCIAS, 8., Campinas. Atas... Campinas, 2011.

GASPARINI, L.J. Por que alguns peixes vivem na água doce e outros, na água salgada? Revista Ciência Hoje das Crianças, v.23, n.213, 2010. 
JUSTINA, A.D.J.; FERLA, M.R. A utilização de modelos didáticos no ensino de genética - exemplo de representação de compactação do DNA eucarioto. Arq Mudi., v.10, n.2, p.35-40, 2006.

KRASILCHIK, Myriam. Prática de ensino de biologia. EdUSP: São Paulo, 2011.

LEMOS, E.S.; MOREIRA, M.A. A avaliação da aprendizagem significativa em biologia: um exemplo com a disciplina embriologia. Aprendizagem Significativa em Revista, v.1, n.2, p. 15-26, 2011.

LIMA, J.H.G.; SIQUEIRA, A.P.P.; COSTA, S. A utilização de aulas práticas no ensino de ciências: um desafio para os professores. Revista Técno-científico do IFSC, v.2, n.2, p.486-495, 2013.

LUCKESI, C.C. Avaliação da aprendizagem: componente do ato pedagógico. Cortez: São Paulo, 2011.

MARTINS, I.; CASSAB, M.; ROCHA, M. B. Análise do processo de re-elaboração discursiva de um texto de divulgação científica para um texto didático. In: ENCONTRO NACIONAL DE PESQUISA EM EDUCAÇÃO EM CIÊNCIAS, 3., 2001, Atibaia. Anais... Atibaia, 2001.

MENEGAT, T. M. C.; CLEMENT, L.; TERRAZZAN, E. A. Textos de divulgação científica em aulas de física: uma abordagem investigativa. In: ENCONTRO NACIONAL DE PESQUISA EM EDUCAÇÃO EM CIÊNCIAS, 6., 2007, Florianópolis. Anais... Florianópolis, 2007.

MOREIRA, M.A. Aprendizaje significativo crítico. Indivisa, Boletin de estúdios e investigacion, v.6, n.2, p.83-101, 2010.

MOREIRA, M.A. O que é afinal aprendizagem significativa? Qurriculum, La Laguna, Espanha, 2012.

MOREIRA, M.A. Unidades de enseñanza potencialmente significativas - UEPS.

Aprendizagem Significativa em Revista, .v.1, n2, p.43-63, 2011 a.

MOREIRA, M.A. Abandono da narrativa, ensino centrado no aluno e aprender a aprender criticamente. Ensino, Saúde e Ambiente, v.4, n.1, p.2-17, 2011 b.

OLIVEIRA, D.B.; LUZ, C.F.S.; SOUZA, A.L.S.; BITENCOURT, M.; SANTOS, M.C. O ensino de Zoologia numa perspectiva evolutiva: análise de uma ação educativa desenvolvida com uma turma do Ensino Fundamental. In: ENCONTRO NACIONAL DE PESQUISADORES EM EDUCAÇÃO DE CIÊNCIAS (ENPEC), 8., 2011. Anais... Campinas, 2011.

PELIZZARI, A.; KRIEGL, M. L.; BARON, M.P.; FINCK, N.T. L.; DOROCINSKI, S.I. Teoria da Aprendizagem Significativa segundo Ausubel. Revista PEC, v.2, n.1, p.37-42, 2002.

PORTO, J.I. R. Você sabia que as piranhas também comem vegetais? Revista Ciência Hoje das Crianças, n.186, 2007.

ROCHA, A.L.F.; MAESTRELLI, S.R.P. O cotidiano escolar socio-historicamente condicionado no ensino de zoologia: uma aproximação da prática docente na rede municipal de Florianópolis. Revista do SBEnBio, v.7, p.581- 593, 2014.

SANTOS, A. B.; GUIMARÃES, C.R.P. A utilização de jogos como recurso didático no ensino de zoologia. REIEC, v.5, n.2, p.52-57, 2010. 
SANTOS, S.Z.S.; TERÁN, A.F. Condições de ensino em zoologia no nível fundamental: o caso das escolas municipais de Manaus-AM. Rev. ARETÉ, v.6, n. 10, p.01-18, 2013a.

SANTOS, S.Z.S.; TERÁN, A.F. O planejamento do ensino de zoologia a partir das concepções de profissionais da educação municipais em Manaus-Amazonas, Brasil. REIEC, v.8, n.2, p.1-12, 2013b.

TEAZANI, T.C.R. O Jogo e os processos de aprendizagem: aspectos cognitivos e afetivos. Educação em Revista, v.7, n.1/2, p.1-16, 2006.

ZABALA, A. A Prática Educativa: Como educar. Porto Alegre, 1998.

ZABALZA, M.A.Diários de aula: um instrumento de pesquisa e desenvolvimento profissional. Artmed: Porto Alegre, 2004. 